\title{
DHA Upregulates FADS2 Expression in Primary Cortical Astrocytes Exposed to Vitamin A
}

\author{
B. DZIEDZIC ${ }^{1}$, D. BEWICZ-BINKOWSKA ${ }^{1}$, E. ZGORZYNSKA ${ }^{1}$, D. STULCZEWSKI ${ }^{1}$, \\ L. WIETESKA ${ }^{2}$, B. KAZA ${ }^{3}$, A. WALCZEWSKA ${ }^{1}$ \\ ${ }^{1}$ Department of Cell-to-Cell Communication, Medical University of Lodz, Lodz, Poland, \\ ${ }^{2}$ Department of Medical Biochemistry, Medical University of Lodz, Lodz, Poland, ${ }^{3}$ Laboratory of \\ Molecular Neurobiology, Neurobiology Center, The Nencki Institute of Experimental Biology, \\ Warsaw, Poland
}

Received July 5, 2017

Accepted January 26, 2018

On-line May 5, 2018

\section{Summary}

The fads2 gene encoding $\Delta 6$-desaturase, the rate-limiting enzyme of the LCPUFA biosynthesis is expressed in astrocytes. Dietary fatty acids, which cross the blood-brain barrier, may regulate the transcription of lipogenic enzymes through activation of transcription factors such as peroxisome proliferator-activated receptors (PPARs). The PPARs form the transcription complex with retinoid $X$ receptors (RXRs) that are activated by 9 -cis retinoic acid, a metabolite of vitamin $A$ (VA). The study examines whether challenge of astrocytes with VA, prior 24-h treatment with palmitic acid (PA), a-linolenic acid (ALA) or docosahexaenoic acid (DHA) has the effect on the FADS2 expression. RT-qPCR showed that in astrocytes not challenged with VA, PA increased fads2 gene expression and DHA decreased it. However, in VA-primed astrocytes, PA doubled the FADS2 mRNA levels, while DHA increased fads2 gene expression, oppositely to non-primed cells. Furthermore, similar changes were seen in VA-primed astrocytes with regard to $\Delta 6$-desaturase protein levels following PA and DHA treatment. ALA did not have any effect on the FADS2 mRNA and protein levels in either VA-primed or non-primed astrocytes. These findings indicate that in the presence of vitamin A, DHA upregulates fads2 gene expression in astrocytes.

\section{Key words}

FADS2 • Vitamin A • Docosahexaenoic acid • a-linolenic acid • Palmitic acid $\bullet$ Astrocytes

\section{Corresponding author}

B. Dziedzic, Department of Cell-to-Cell Communication, Medical University of Lodz, Mazowiecka 6/8, 92-415 Lodz, Poland. E-mail: barbara.dziedzic@umed.lodz.pl

In mammals, the biosynthesis of long-chain polyunsaturated fatty acids (LCPUFAs) from 18-carbon chain essential fatty acids is carried out by the elongases, and $\Delta 5$ - and $\Delta 6$-desaturases in the endoplasmic reticulum (Sprecher et al. 1995). These desaturases are encoded by the fads 1 and fads 2 genes, respectively, and together with the fads 3 gene on human chromosome 11 (11q12-13.1) create the cluster, which genetic variations determine the LCPUFA levels in cell membrane and in circulation (Marquardt et al. 2000, Mathias et al. 2014). The $\Delta 6$-desaturase is the rate-limiting enzyme of the LCPUFA synthesis; it introduces the double cis bonds at both n-3 and n-6 LCPUFAs by $\mathrm{O}_{2}$-dependent subtraction of two hydrogens from a methylene group of hydrocarbon chains.

Dietary fatty acids are signaling molecules that regulate biological processes via regulation of metabolic enzyme gene transcription. It has been demonstrated that LCPUFAs downregulate the transcription of key lipogenic enzymes, including $\Delta 6$-desaturase (FADS2) (Clarke and Jump 2001), acting as feedback inhibitors of their own synthesis. In the cells, nonesterified PUFAs bind to the sensors that belong to the family of 
peroxisome proliferator-activated receptors (PPARs) (Bordoni et al. 2006). PPARs heterodimerize with retinoid $X$ receptors (RXRs) activated by vitamin $A$ derivatives, such as 9-cis retinoic acid (Zapata-Gonzalez et al. 2007), and bind to regulatory elements in the promoters of responsive genes (Hermanson et al. 2002). The PPAR isoforms (PPAR $\alpha, \operatorname{PPAR} \beta / \delta$, and PPAR $\gamma$ ) and $\operatorname{RXR} \beta$ isotype have been found in cultured astrocytes by fluorescence imaging and Western blot (Chistyakov et al. 2015). A recent study utilizing quantitative PCR and double immunofluorescence showed high expression of PPAR $\alpha$ and low expression of PPAR $\gamma$ in the mouse cortical astrocytes (Warden et al. 2016). Furthermore, interaction between DHA and RXR has been demonstrated in the brain (Lengqvist et al. 2004).

Docosahexaenoic acid (DHA) esterified to $s n-2$ position of glycerophospholipids is the most abundant LCPUFA in the brain (Stillwell and Wassall 2003). The high level of DHA-containing phospholipids plays an important role in maintaining neuronal membrane fluidity, which creates a molecular environment suitable for the operation of transmembrane proteins with membrane-associated signaling proteins (Akbar et al. 2005). As astrocytes, unlike neurons, express FADS2 and possess activity in synthesis of 22-carbon PUFAs (Moore et al. 1991), it has been proposed that astrocytes supply lipids to neurons (Tabernero et al. 2001). The regulation of fads 2 gene expression by dietary fatty acids has been extensively investigated in the liver (Nara et al. 2002); however, the mechanism of fatty acid regulation of this gene in astrocytes remains unknown. To better understand this process, the present study examines the effect of palmitic acid (PA; C16:0), $\alpha$-linolenic acid (ALA; 18:3 n-3), and DHA (22:6 n-3) on FADS2 mRNA and protein levels in rat astrocytes. Since vitamin A derivatives activate RXRs, the obligatory heterodimer of the PPAR transcription factor, the study investigates whether pretreatment of astrocytes with vitamin A may influence fads 2 gene transcription, which is regulated by fatty acids.

Primary astrocytes were prepared from newborn 1-2 days old Wistar rats as previously described (Zawadzka and Kaminska 2003). The study protocol was approved by the Government Ethical Committee for Animal Care. Cells were cultured in high-glucose DMEM with $10 \% \mathrm{FBS}$ and antibiotics in $75 \mathrm{~cm}^{2}$ flasks at $37{ }^{\circ} \mathrm{C}$ and $5 \% \mathrm{CO}_{2}$ atmosphere then seeded into 6-well plates $\left(5 \times 10^{5}\right.$ cells/well $)$, or into $80 \mathrm{~mm}$ Petri dishes $\left(1.5 \times 10^{6}\right.$ cells/dish). After the growth phase, astrocytes were pretreated with $10 \mu \mathrm{M}$ vitamin A (VA, Medana Pharma SA, Poland) or cultured in DMEM for $24 \mathrm{~h}$, followed by incubation with PA, ALA, and DHA at concentration of $50 \mu \mathrm{M}$ for next $24 \mathrm{~h}$. Control cells were cultured in DMEM.

The fads 2 gene expression was examined by reverse transcription quantitative polymerase chain reaction PCR (RT-qPCR). Total RNA was isolated from astrocytes using TRIZOL RNA reagent (Invitrogen Life Technologies, USA). The quantity and purity of the extracted RNA was checked with a PicoDrop Microliter UV/Vis Spectrophotometer. A ratio A 260/280 of 1.9- 2.1 was taken as pure RNA. The RNA quality was determined using a 2100 Bioanalyzer (Agilent Technologies, USA). The RNA samples used in the reverse transcription reaction were calculated and diluted to the same concentration and quality (RIN value was $>7$ ). Reverse transcription of $1 \mu \mathrm{g}$ of total RNA was performed in a total $20 \mu \mathrm{l}$ using Superscript III reverse/ ImProm-II ${ }^{\mathrm{TM}}$ reverse transcriptase (Promega, USA), dNTPs and random hexamer primers (Invitrogen Life Technologies, USA) for $1 \mathrm{~h}$ at $50^{\circ} \mathrm{C}$. The obtained cDNA was used for qPCR reaction. Expression of the housekeeping gene glyceraldehyde-3-phosphate dehydrogenase $(G A P D H)$ was used as an internal control. The following primer pairs: 5'GTTCTTCTT TCTCCTCCTGTCCC-3' (forward) and 5'-CATTGC CGAAGTACGAGAGGAT-3' (reverse); 5'-CATGGC CTTCCGTGTTCCTA-3' (forward) and 5'-CCTGCT TCACCACCTTCTTGA-3' (reverse) were used to detect the mRNA of FADS2 and GAPDH, respectively. Gene expression was quantified using an ABI Prism 7000 Sequence Detection System (Applied Biosystems, USA) using a Brilliant III SYBR QPCR kit (Agilent Technologies) according to the manufacturer's protocol. Each sample was assayed in triplicate in independent reactions. PCR efficiency was validated with a standard curve. The results were analyzed according to the $2^{-\Delta \Delta C t}$ method. Relative gene expression was normalized to GAPDH expression and presented as relative quantification (RQ), i.e. fold change compared to the untreated control with RQ value of 1 .

The FADS2 protein level was determined by Western blot using Thermo Scientific-Pierce reagents and antibodies supplied by Santa Cruz Biotechnology (USA). Astrocytes were lysed with RIPA buffer (25 mM Tris, $150 \mathrm{mM} \mathrm{NaCl}, 0.1 \%$ SDS, $0.5 \%$ sodium deoxycholate, $1 \% \mathrm{NP}-40$ and protease inhibitors cocktail) and total protein levels were determined by BCA Protein Assay 
Kit. The protein samples $(20 \mu \mathrm{g})$ were separated by SDS-PAGE, transferred onto the nitrocellulose membrane and incubated overnight with rabbit polyclonal anti-FADS2 antibodies (sc-98480) followed by two-hour incubation with mouse anti rabbit IgG horseradish peroxidase-conjugated secondary antibodies (sc-2357). The luminescence signal of bands was obtained using Pierce ECL Western Blotting Substrate and visualized on Amersham Hyperfilm ECL. Densitometric analysis was performed with Image-J software. Beta-actin was used as a loading control. To detect $\beta$-actin protein, the same blot was reprobed with mouse anti- $\beta$-actin monoclonal antibody (sc-47778), after stripping in buffer containing DTT; the detection was performed using secondary antibody-HRP conjugate, as described above.

To compare the effects of three different fatty acids, one-way analysis of variance (ANOVA) followed by the Newman-Keuls multiple comparison test was used. P-values $<0.05$ were considered significant.

The effects of fatty acids differing in the numbers of double bonds on fads 2 gene expression in astrocytes non-primed and primed with vitamin $\mathrm{A}$ are shown in Figure 1A. The level of the FADS2 transcript in astrocytes incubated with DHA was reduced by half $(p<0.01)$, but was increased in PA-treated cells $(p<0.01)$ compared to controls. ALA did not change the FADS2 mRNA level compared to control cells.

However, instead of reducing the level of FADS2 mRNA in astrocytes preincubated with vitamin A, DHA upregulated the levels fivefold compared to control cells $(p<0.0001)$. Likewise, PA doubled the FADS2 mRNA in VA-primed astrocytes compared to cells untreated with vitamin A. The administration of ALA in combination with retinol did not affect the FADS2 mRNA levels.

These effects on fads 2 gene expression in VA-primed astrocytes were reflected in the levels of FADS2 protein. As Figure 1B shows, densitometric analysis of the bands corresponding to FADS 2 revealed an increase in FADS2 protein levels after PA $(p<0.01)$ and DHA $(\mathrm{p}<0.001)$ treatment in VA-primed astrocytes compared to the control cells. However, in astrocytes not primed with VA, the FADS2 protein levels after incubation with fatty acids did not differ from those observed in the control cells. Similarly, incubation with ALA did not influence the FADS2 protein levels in VA-primed astrocytes.
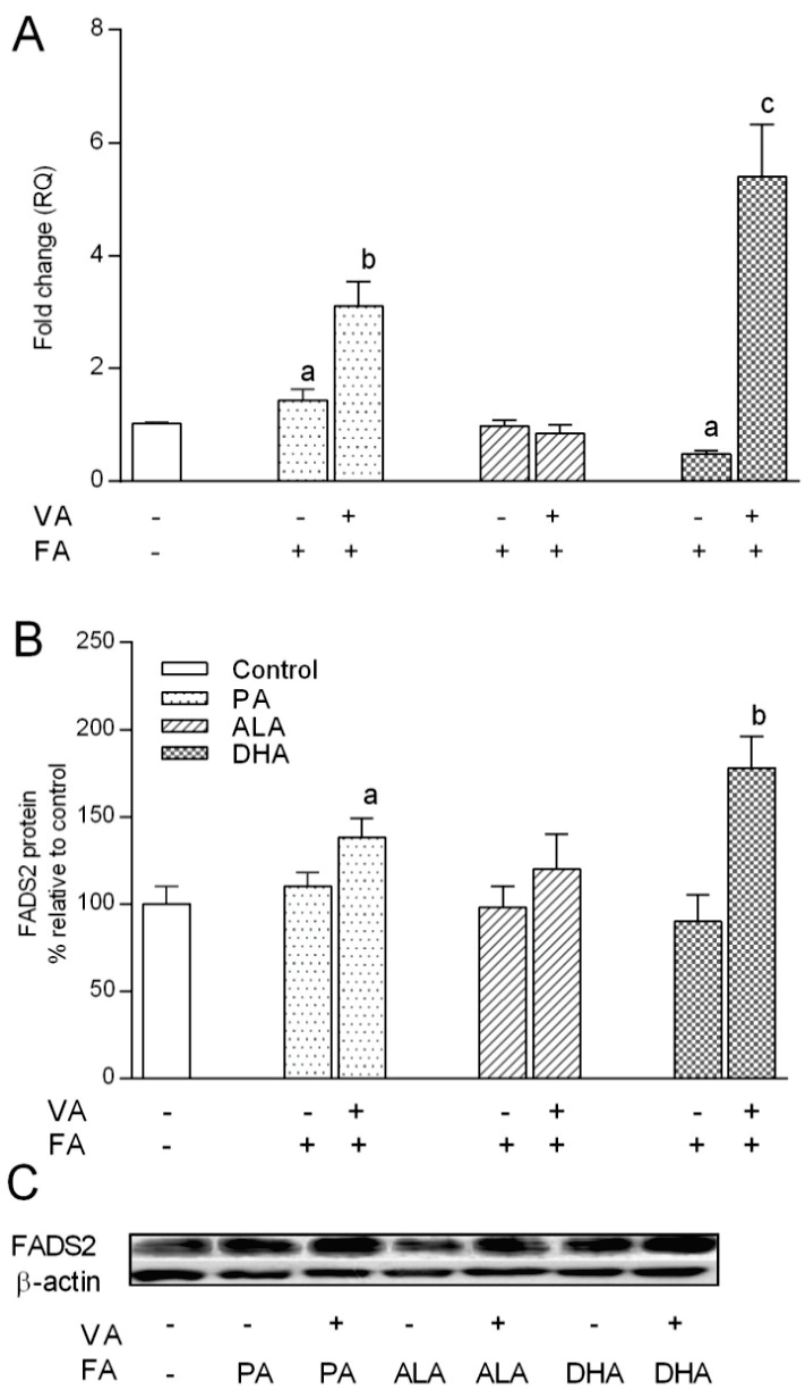

Fig. 1. FADS2 mRNA (A) and FADS2 protein (B) levels after palmitic acid (PA), a-linolenic acid (ALA) and docosahexaenoic acid (DHA) treatment in astrocytes primed or non-primed with vitamin $A(V A)$. Bottom (C), the representative immunoblot for FADS2 and $\beta$-actin proteins. Data are means \pm SEM ( $n=6$ for FADS2 mRNA and $n=2$ for FADS2 protein). ${ }^{a} p<0.01,{ }^{b} p<0.001$, ${ }^{c} p<0.0001$ compared to astrocytes cultured in DMEM alone.

In the brain, a high level of DHA should be maintained after the intense DHA accretion in late fetal and infant period (Innis 2008). However, during aging and under adverse conditions, such as the production of inflammatory mediators by activated microglia and astrocytes, which enhances phospholipid deacylation via activation of phospholipase A2, the DHA level in neuronal membranes decreases; this results in an imbalance in the cellular homeostasis, which is known to be associated with various types of neuropathology. Since astrocytes express a functional FADS2 (Moore 2001) they may be a potential source of DHA for neurons, similarly to their role in cholesterol supply to 
neurons (Pfrieger and Ungerer 2011). Therefore, it is important to recognize the regulation of FADS2 expression by exogenous fatty acids in astrocytes.

The molecular mechanism of gene transcription regulation by fatty acids, well recognized in hepatocytes, involves the activation of PPARs and sterol regulatory elements binding protein 1 (SREBP-1) (Georgiadi and Kersten 2012). It has been demonstrated that in rat hepatocytes, various PUFAs differently activate PPARs. Oleic acid and DHA had little or modest effects on the PPAR-regulated target genes, while eicosapentaenoic acid significantly enhanced the PPAR-dependent target gene transcription (Pawar and Jump 2003). Regarding the activation of genes involved in de novo lipogenesis by SREBP-1c, it has been found that PUFAs generally suppress the transcription of a wide range of hepatic lipogenic genes, either by inhibition of SREBP gene transcription (Xu et al. 1999), or by suppression of SREBP-1 proteolytic processing (Takeuchi et al. 2010). Moreover, SREBP-1 expression has been documented in different regions of rodent brains (Camargo et al. 2012), as well the contribution of SREBPs in cholesterol and fatty acid synthesis in astrocytes (Okamoto et al. 2006).

The present results demonstrate that in the absence of vitamin A, fatty acids regulate FADS2 gene expression in astrocytes in different ways: saturated PA slightly increased FADS2 transcript levels while DHA diminished them. The inhibitory effect of DHA on FADS2 gene expression may have a similar mechanism to that observed in hepatocytes, where DHA acts as a potent suppressor of SREBP-1 abundance in the nucleus by accelerating its proteasomal degradation (Botolin et al. 2006). However, following DHA treatment, FADS2 mRNA and protein levels in VA-primed astrocytes were higher than in those not primed with VA; similarly, following PA treatment, FADS2 expression was enhanced more in VA-primed cells than in non-primed with VA astrocytes.
The precise mechanism of this effect is not recognized yet, however, we speculate that it may be similar to the mechanisms of the regulation of nuclear receptor by fatty acids (Jump 2013). The PPAR response element in the promoter of the FADS2 gene was identified as direct repeat sequence 1 (DR1) (Tang et al. 2003, Rakhshandehroo et al. 2010). To carry out most of their functions, the PPARs must heterodimerize with $\mathrm{RXR}$; as this is a heterodimerization partner of about twenty other nuclear receptors, some heterodimers also share the same DR1 element. Both PPAR and RXR mRNAs have been found in cortical astrocytes (Cullingford et al. 1998). Dietary retinol is converted to 9-cis isomer and all-trans retinoic acid (Conaway et al. 2013), the ligands of RXRs and RAR, respectively, which could form a variety of heterodimers competing to bind to the DR1 and for cross-talk with the PPAR:RXR heterodimer (Chan and Wells 2009). As a result, the coactivators can have better access to the PPAR:RXR complex to enhance FADS2 promoter activity.

In conclusion, vitamin A may affect LCPUFA production in astrocytes, which is especially important for upregulation of $f a d s 2$ gene expression by DHA. These findings can contribute to the development of a molecular strategy to increase LCPUFA synthesis by astrocytes.

\section{Conflict of Interest}

There is no conflict of interest.

\section{Acknowledgements}

The authors thank dr. Elzbieta Płuciennik, Department of Molecular Carcinogenesis, Medical University of Lodz, for support in molecular determinations. This work was supported by The National Center for Research and Development for bilateral co-operation with Taiwan (grant DKO/PL-TW1/4/2013) and grant 503/0-07904/503-01-001 from the Medical University of Lodz.

\section{References}

AKBAR M, CALDERON F, WEN Z, KIM HY: Docosahexaenoic acid: a positive modulator of Akt signaling in neuronal survival. Proc Natl Acad Sci U S A 102: 10858-10863, 2005.

ALLENBY G, BOCQUEL MT, SAUNDERS M, KAZMER S, SPECK J, ROSENBERGER M, LOVEY A, KASTNER P, GRIPPO JF, CHAMBON P: Retinoic acid receptors and retinoid X receptors: interactions with endogenous retinoic acids. Proc Natl Acad Sci U S A 90: 30-34, 1993.

BORDONI A, DI NUNZIO M, DANESI F, BIAGI PL: Polyunsaturated fatty acids: from diet to binding to PPARs and other nuclear receptors. Genes Nutr 1: 95-106, 2006. 
BOTOLIN D, WANG Y, CHRISTIAN B, JUMP BD: Docosahexaneoic acid (22:6, n-3) regulates rat hepatocyte SREBP-1 nuclear abundance by Erk- and 26S proteasome-dependent pathways. J Lipid Res 47: 181-192, 2006.

CAMARGO N, SMIT AB, VERHEIJEN MH: SREBPs: SREBP function in glia-neuron interactions. FASEB $J$ 276: 628-636, 2009.

CHAN LS, WELLS RA: Cross-talk between PPARs and the partners of RXR: a molecular perspective. PPAR Res 2009: 925309, 2009.

CHISTYAKOV DV, ALESHIN SE, ASTAKHOVA AA, SERGEEVA MG, REISER G: Regulation of peroxisome proliferator-activated receptors (PPAR) $\alpha$ and $-\gamma$ of rat brain astrocytes in the course of activation by toll-like receptor agonists. $J$ Neurochem 134: 113-124, 2015.

CLARKE SD, JUMP DB: Dietary polyunsaturated fatty acid regulation of gene transcription. Annu Rev Nutr 14: 83-89, 2001.

CONAWAY HH, HENNING P, LERNER UH: Vitamin A metabolism, action, and role in skeletal homeostasis. Endocr Rev 34: 766-797, 2013.

CULLINGFORD TE, BHAKOO K, PEUCHEN S, DOLPHIN CT, PATEL R, CLARCK JB: Distribution of mRNAs encoding the peroxisome proliferator-activated receptor $\alpha, \beta$, and $\gamma$ and the retinoid $\mathrm{X}$ receptor $\alpha, \beta$, and $\gamma$ in rat central nervous system. J Neurochem 70: 1366-1375, 1998.

GEORGIADI A, KERSTEN S: Mechanisms of gene regulation by fatty acids. Adv Nutr 3: 27-134, 2012.

HERMANSON O, GLASS CK, ROSENFELD MG: Nuclear receptor coregulators: multiple modes of modification. Trends Endocrinol Metab 13: 55-60, 2002.

INNIS SM: Dietary omega 3 fatty acids and the developing brain. Brain Res 1237: 35-43, 2008.

JUMP DB: Fatty acid-regulated transcription factors in the liver. Annu Rev Nutr 33: 249-269, 2013.

LENGQVIST J, MATA DE URQUIZA A, BERGMAN AC, WILLSON TM, SJÖVALL J, PERLMANN T, GRIFFITHS WJ: Polyunsaturated fatty acids including docosahexaenoic and arachidonic acid bind to the retinoid X receptor alpha ligand-binding domain. Mol Cell Proteomics 3: 692-703, 2004.

MARQUARDT A, STOHR H, WHITE K, WEBER BHF: cDNA cloning, genomic structure, and chromosomal localization of three members of the human fatty acid desaturase family. Genomics 66: 175-183, 2000.

MATHIAS RA, PANI V, CHILTON FH: Genetic variants in the fads gene: implications for dietary recommendations for fatty acid intake. Curr Nutr Rep 3: 139-148, 2014.

MATSUZAKA T, SHIMANO H, YAHAGI N, AMEMIYA-KUDO M, YOSHIKAWA T, HASTY AH, TAMURA Y, OSUGA J, OKAZAKI H, IIZUKA Y, TAKAHASHI A, SONE H, GOTODA T, ISHIBASHI S, YAMADA N: Dual regulation of mouse Delta5- and Delta6-desaturase gene expression by SREBP-1 and PPAR $\alpha$. J Lipid Res 43: 107-114, 2000.

MOORE SA: Polyunsaturated fatty acid synthesis and release by brain-derived cells in vitro. J Mol Neurosci 16: 195-200, 2001.

MOORE SA, YODER E, MURPHY S, DUTTON GR, SPECTOR AA: Astrocytes, not neurons, produce docasahexaenoic acid (22:6 omega-3) and arachidonic acid (20:6 omega-6). J Neurochem 56: 518-524, 1991.

NARA TY, HE WS, TANG C, CLARKE SD, NAKAMURA MT: The E-box like sterol regulatory element mediates the suppression of human delta-6 desaturase gene by highly unsaturated fatty acids. Biochem Biophys Res Commun 296: 111-117, 2002.

OKAMOTO K, KAKUMA T, FUKUCHI S, MASAKI T, SAKATA T, YOSHIMATSU H: Sterol regulatory element binding protein (SREBP)-1 expression in brain is affected by age but not by hormones or metabolic changes. Brain Res 1081: 19-27, 2006.

PAWAR A, JUMP DB: Unsaturated fatty acid regulation of peroxisome proliferator activated receptor $\alpha$ activity in rat primary hepatocytes. J Biol Chem 278: 35931-35939, 2003.

PFRIEGER FW, UNGERER N: Cholesterol metabolism in neurons and astrocytes. Prog Lipid Res 50: 357-371, 2011.

RAKHSHANDEHROO M, KNOCH B, MÜLLER M, KERSTEN S: Peroxisome proliferator-activated receptor alpha target genes. Cell Mol Life Sci 61: 393-416, 2010.

SPRECHER H, LUTHRIA DL, MOHAMMED BS, BAYKOUSHEVA SP: Reevaluation of the pathways for the biosynthesis of polyunsaturated fatty acids. J Lipid Res 36: 2471-2477, 1995. 
STILLWELL W, WASSALL SR: Docosahexaenoic acid: membrane properties of a unique fatty acid. Chem Phys Lipids 126: 1-27, 2003.

TABERNERO A, LAVADO EM, GRANDA B, VELASCO A, MEDINA JM: Neuronal differentiation is triggered by oleic acid synthesized and released by astrocytes. J Neurochem 79: 606-616, 2001.

TAKEUCHI Y, YAHAGI N, IZUMIDA Y, NISHI M, KUBOTA M, TERAOKA Y, YAMAMOTO T, MATSUZAKA T, NAKAGAWA Y, SEKIYA M, IIZUKA Y, OHASHI K, OSUGA J, GOTODA T, ISHIBASHI S, ITAKA K, KATAOKA K, NAGAI R, YAMADA N, KADOWAKI T, SHIMANO H: Polyunsaturated fatty acids selectively suppress sterol regulatory element-binding protein-1 through proteolytic processing and autoloop regulatory circuit. J Biol Chem 285: 11681-11691, 2010.

TANG C, CHO HP, NAKAMURA MT, CLARKE SD: Regulation of human $\Delta-6$ desaturase gene transcription: identification of a functional direct repeat-1 element. J Lipid Res 44: 686-695, 2003.

WARDEN A, TRUITT J, MERRIMAN M, PONOMAREVA O, JAMESON K, FERGUSON LB, MAYFIELD RD, HARRIS RA: Localization of PPAR isotypes in the adult mouse and human brain. Sci Rep 6: 27618, 2016.

XU J, NAKAMURA MT, CHO HP, CLARKE SD: Sterol regulatory element binding protein-1 expression is suppressed by dietary polyunsaturated fatty acids. J Biol Chem 274: 23577-23583, 1999.

ZAPATA-GONZALEZ F, RUEDA F, PETRIZ J, DOMINGO P, VILLARROYA F, DE MADARIAGA A, DOMINGO JC: 9-cis-retinoic acid (9cRA), a retinoid X receptor (RXR) ligand, exerts immunosuppressive effects on dendritic cells by RXR-dependent activation: inhibition of peroxisome proliferator-activated receptor gamma blocks some of the 9cRA activities, and precludes them to mature phenotype development. J Immunol 178: 6130-6139, 2007.

ZAWADZKA M, KAMINSKA B: Immunosuppressant FK506 affects multiple signaling pathways and modulates gene expression in astrocytes. Mol Cell Neurosci 22: 202-209, 2003. 